is very little common ground in the experiments. Noreover, using a manual response of the kind he employed unnecessarily complicates the interpretation and most probably neutralizes the "TTT," for it is becoming apparent from a number of other studies that movements elicited from proximal muscle system give no difference, whereas responses requiring cerebral exclusively-individual finger control reveal "TT" $T$ " differences.

The idea of trying to figure out the callosal code by using reaction time is upon us. It may fade. It's not as easy as it sounds. Nonetheless, within the year there have been a number of papers on the subject (Moscovitch \& Catlin, 1970; Bradshaw \& Perriment, 1970; Klatzky ${ }^{1}$ ). These authors, using different responses, different stimuli, and different almost everything else, found differences in transmission time ranging from. 10 to 60 msec. Finally, I can only urge those interested in the approach to join in.

\section{REFERENCES}

AKELAITIS, A. $\mathbf{J}$. Studies on corpus callosum; higher visual functions in each homonymous field following complete section of corpus callosum. Archives of Neurological Psychiatry (Chicago), 1941, 45.788

\title{
The role of interference and
} trace decay in the retention
of a simple psychomotor task*

\author{
STEPHEN D. SOUTHALL $\dagger$ and KENNETH A. BLICK \\ University of Richmond, Richmond, Va. 23173
}

The purpose of the present study was to show whether interference theory and/or trace decay theory account for the forgetting found in motor short-term memory. One variable was the number of prior responses $(0$ to 6$)$ which the $S$ experienced on a linear slide apparatus; another variable was the length of the retention interval $(5,40$, and $75 \mathrm{sec})$. There were no significant effects due to retention interval, number of prior responses, or the interaction between retention interval and prior responses.

The role that interference plays in verbal short-term memory (STM) has been established for some time, but its

* This research was supported in part by a Faculty Research Grant from the University of Richmond.

+Now at the University of Virginia.
AKELAITIS, A. J. Studies on corpus callosum; study of language functions (tactile and visual, lexia and gxaphia) unilaterally following section of corpus callosum. Journal of Neuropathological \& Experimental Neurology, 1943, 2, 226

AKELAITIS, A. J. Study of gnosis, praxis, and language following section of corpus callosum and anterior commissure. Journal of Neurosurgery, 1944, 1 , 94

AKELAITIS, A. J., RISTEEN, A. W., HERREN, R. Y., \& VAN WAGENEN, W. P. Studies on corpus callosum; contribution to study of dyspraxia and Neurological Psychiatry (Chicago), 1942, 47,971 Laterality effects and choice reaction time in a unimanual two-finger task. Perception \& Psychophysics, 1970, 7, 185-188.

MOSCOVITCH, M., \& CATLIN, J. Interhemispheric transmission of information: Measurement in normal man. Psychonomic Science, 1970, 18, 211-213.

POFFENBERGER, A. T. Reaction time to retinal stimulation with special reference to the time lost in conduction through nerve centers. Archives of Psychology (New York), 1912, No. 23.

\section{NOTE}

1. Klatzky, R. L. Interhemispheric transfer of test stimulus representations in memory scanning. In preparation. apraxia of corpus callosum. Archives of

BRADSHAW, J. L., \& PERRIMENT, A. D.

trace decay theory, or a combination of the two best accounts for the forgetting shown in motor STM.

Adams \& Dijkstra (1966) examined the retention of a linear motor response in which the basic variables were length of retention interval and number of reinforcements or trials before recall. Absolute error was found to be positively related to length of retention interval, and consequently, Adams \& Dijkstra (1966) interpreted their results in terms of a rapidly decaying memory trace, which became increasingly stable with reinforcement. Stelmach ( 1969 a), using a simple lever-positioning task, employed the three independent variables of magnitude of movement, retention interval, and number of prior positioning responses. Absolute error was found to be positively related to the number of prior positioning responses and to the length of the retention interval, but the magnitude of the movement was found to be nonsignificant. He considered the role of proactive interference in his results but seemed to favor the decay of the memory traces as the best explanation. However, in a similar study, Stelmach (1969b) found that absolute errors at recall were inversely related to the similarity of prior responses and that forgetting was found to be an increasing function of the retention interval. Stelmach (1969b) noted that the results concerning the similarity of responses were in direct opposition to the findings usually observed in verbal tasks and were not consistent with the predictions from interference theory.

More recently, Pepper \& Herman (1970) performed a series of five experiments measuring the retention of the magnitude of the force of a knob which was pushed or pulled through the vertical dimension in an attempt to establish whether decay, interference, or a combination of the two was the cause of the forgetting shown in motor STM. Pepper \& Herman (1970), by application of a second force response during the retention interval, showed that interference effects, traceable to the interpolated task, can be demonstrated for motor STM. The role of trace decay and interference theory in the area of motor STM is still nebulous, and it was the purpose of the present experiment to establish precisely the role of trace decay theory and/or interference theory in motor STM.

role in motor STM has not yet been confirmed. Although there have been many studies of verbal STM (Conrad \& Hille, 1958; Keppel \& Underwood, 1962; Murdock, 1961; Peterson \& Peterson, 1959), there have been relatively few studies on short-term retention of motor responses. It is not yet clear whether interference theory.

\section{METHOD}

One hundred and five undergraduates from the University of Richmond participated in the experiment. Fifteen males and 20 females served in each of the three retention intervals 
The apparatus was a block of wood, $5 \mathrm{~cm}$ high, $7 \mathrm{~cm}$ wide, and $68 \mathrm{~cm}$ long, with a 2-cm-wide groove cut down the length of the board in the center of the $7 \cdot \mathrm{cm}$ side. A slide which measured $2.5 \mathrm{~cm}$ long and slightly less than $2 \mathrm{~cm}$ wide fit snugly in the groove and had a knob on the top which enabled the Ss to move the slide in the groove. Another slide, used as a stop by the E, was put in the groove during the practice trials and removed during the recall trials.

All Ss came into the experimental room and were seated across the table from the $\mathrm{E}$. They were told that they were to remember and duplicate as well as possible a series of movements along a straight line which they were to make on the slide apparatus in front of them. They were told that on the instruction, "Move," they were to move the slide from right to left by means of the knob until they hit a stop. After $3 \mathrm{sec}$ the instruction, "Return," was given, and they returned the slide to the starting position. It was at this point that the retention interval of 5,40 , or $75 \mathrm{sec}$ began. During this interval $S$ was not to move his hand from the knob but could rest his arm on the desk. On the instruction, "Estimate," he was to attempt to duplicate his response in one continuous movement.

After the previous instructions had been read to the $S$ and any questions answered, the $\mathrm{S}$ was blindfolded. He grasped the knob on top of the slide, and on the instruction, "Move," he moved the slide until he hit a stop. The S's hand remained in this position for 3 sec. On the instruction, "Return," he returned the slide to the starting position which was at the end of the groove at the S's right. A permanent stop was located there, to stop the slide when the $S$ had moved it back to the starting position.

There were seven different lengths of movements which the Ss made. The lengths were $10,14,18,22,26,30$, and $34 \mathrm{~cm}$. The lengths were presented in seven different randomized sequences, with each length appearing in each ordinal position once, in order to prevent any sequential effect from smaller to larger lengths, or vice versa. In addition, the seven randomized sequences occurred equally often under each time interval and five $S s$ serving in each sequence.

After the $\mathbf{S}$ moved back to the starting position, the $\mathrm{E}$ started timing the retention interval of 5,40 , or $75 \mathrm{sec}$. At the end of the retention period, the $E$ gave the instruction, "Estimate," at which time the S attempted to duplicate his response. After the $S$ had made the continuous movement, he removed his hand from the slide, and the $\mathrm{E}$ started timing the
Table 1

Mean Absolute Error (in Millimeters) for the Seven Prior Response Conditions at the Three Retention Intervals

\begin{tabular}{ccccc}
\hline \multirow{2}{*}{$\begin{array}{c}\text { Number } \\
\text { of Prior }\end{array}$} & \multicolumn{2}{c}{ Retention Intervals } \\
\cline { 2 - 4 } Responses & 5 & 40 & 75 & Group \\
\hline Sec & Sec & Sec & Means \\
\hline 0 & 23 & 28 & 28 & 26.3 \\
1 & 23 & 22 & 25 & 23.3 \\
2 & 30 & 32 & 23 & 28.3 \\
3 & 25 & 25 & 25 & 25.0 \\
4 & 24 & 23 & 28 & 25.0 \\
5 & 23 & 24 & 24 & 23.7 \\
6 & 22 & 23 & 28 & 24.3 \\
Group & 24.3 & 25.3 & 25.8 & \\
Means & & & &
\end{tabular}

intertrial interval of $20 \mathrm{sec}$. During the intertrial interval the $E$ recorded the length of the $S$ 's response. After $E$ recorded the response to the nearest millimeter, he moved the slide back to the starting position and told the $S$ to put his hand on the slide and prepare for another trial.

\section{RESULTS AND DISCUSSION}

Recall scores for each $S$ were calculated as the absolute error in millimeters from perfect target reproduction. The mean absolute error for each of the seven prior response conditions at the three retention intervals is shown in Table 1. Each cell mean is based on $35 \mathrm{Ss}$, and visual inspection of the cell means reveals no apparent trends. According to the group means, absolute error does not appear to increase as the number of prior responses increases, nor does absolute error show any appreciable change over the three retention intervals.

A two-factor analysis of variance with repeated measures was performed on the data, using the .05 level of significance, and all comparisons produced $F<1$. Neither retention interval nor number of prior responses was significant. The interaction of retention interval and number of previous responses was also nonsignificant.

A number of experiments in motor STM have found that retention of a simple motor response is a decreasing function of the length of the retention interval (Adams \& Dijkstra, 1966; Stelmach, 1969a, b; 1970). In addition, the effect of interference in motor STM has been demonstrated in some studies (Stelmach, 1969a; Pepper \& Herman, 1970), while other studies report no effect due to interference (Stelmach, 1969b, 1970). Since the results of both retention interval and number of prior responses in the present study were nonsignificant, no conclusions can be drawn concerning the roles of proactive interference or decay of memory trace.
One reason why the results in the present study were nonsignificant could have been the manner in which the prior responses were administered. Stelmach (1969a) administered either two or four prior positioning responses immediately before the target position response. He then had the $S$ recall the responses in reverse order of presentation, but, unknown to the $S$ he only recorded the target position response. The difference between Stelmach's study and the present one is that his prior positioning responses were not recalled until after the target position response, while in the present study each response was recalled before another was administered. This could be the reason that interference was not shown in the present study. After a response was administered and recalled, it could be dismissed by the $S$ and he could concentrate on the next, whereas in Stelmach's study the S had to retain either three or five responses at one time; this, therefore, produced the interference that evidenced itself in Stelmach's study. Presumably, a combination of Stelmach's method of producing interference and the present experimental design would provide a more definitive answer concerning the role of interference and trace decay in motor STM. According to Stelmach $(1969 b)$, "When there is more data available on the short-term retention of motor responses, it will be better known whether motor behavior follows the same empirical laws that govern verbal responses [p. 43]."

\section{REFERENCES}

ADAMS, J. A., \& DIJKSTRA, S. Short-term memory for motor responses. Journal of Experimental Psychology, 1966, 71 , 314-318.

CONRAD, R., \& HILLE, B. A. Decay theory of immediate memory and paced recall. Canadian Journal of Psychology, $1958,12,1-6$.

KEPPEL, G., \& UNDERWOOD. B. J. Proactive inhibition in short-term retention of single items. Journal of Verbal Learning \& Verbal Behavior, $1962,1,153-161$

MURDOCK, B. B., JR. The retention of individual items. Journal of Experimental Psychology, 1961, 62, 618-625.

PEPPER, R. L., \& HERMAN, L. M. Decay and interference effects in the short-term retention of a discrete motor act. Journal of Experimental Psychology Monograph, 1970, 83, No. 2, Part 2, 1-18.

PETERSON, L. R., \& PETERSON, M. J Short-term retention of individual verbal items. Journal of Experimental Psychology, 1959, 58, 193-198.

STELMACH, G. E. Prior positioning responses as a factor in short-term retention of a simple motor task. Journal of Experimental Psychology, 1969a, 81, 523-526.

STELMACH, G, E. Short-term motor retention as a function of response-similarity. Journal of Motor Behavior, 1969b, 1, 37-44.

STELMACH, G. E. Kinesthetic recall and information reduction activity. Journal of Motor Behavior, 1970, 2, 183-194. 